\title{
The Preparation of Jam: Using Star Fruit
}

\author{
Irene Darkwa \\ Department of Hospitality Management, Takoradi Polytechnic \\ P. O. Box 256, Takoradi, Ghana
}

Tel: 233-541-013-708Ｅ-mail: reney2013@gmail.com

\author{
Nana Ama Boansi Boakye \\ Department of Hospitality Management, Takoradi Polytechnic \\ P. O. Box 256, Takoradi, Ghana
}

Tel: 233-244-419-446 E-mail: nabboansi@yahoo.com

\author{
Received: July 12, $2016 \quad$ Accepted: August 3, $2016 \quad$ Published: September 25, 2016 \\ doi:10.5296/gjes.v2i2.10032ＵRL: http://dx.doi.org/10.5296/gjes.v2i2.10032
}

\begin{abstract}
Fruits are packed with vitamins, minerals and antioxidants that help with the body's maintenance and development. During fruit-bearing season, the fruits are in abundance and due to their high perishability, they sometimes get spoilt and rot before they are consumed. To extend the shelf life they can be used to produce jam. Chopped or crushed fruits can be used to make jam by adding sugar to make a mixture which is then round up when placed on a spoon. The objectives of the study were to find out if star fruit can be used to produce jam, assess the taste, aroma, flavor, color, appearance and aftertaste of the star fruit jam, examine if the star fruit jam will be accepted by customers, evaluate if customers can be encouraged to patronize the jam. The star fruit jam was produced at the Hospitality Management Department at Takoradi Polytechnic and a sensory analysis was conducted to analyze the color, aroma, flavor, texture, taste, after taste and its overall acceptance. A questionnaire was used to solicit information from 98 respondents which comprised of students, lecturers and non-teaching staff. The sample was obtained using convenience sampling technique. The findings revealed that the production of star fruit jam was possible and was accepted by the respondents as they indicated that the sensory attributes that is, (the color, taste, aroma, flavor, texture, after-taste and overall acceptability) of the pineapple, star fruits and the pineapple and star fruit jams were generally very good.
\end{abstract}

Keywords: Star fruit, Jam, Sensory analysis, Flavor, Overall acceptability 


\section{Introduction}

Fruits are mother nature's unique medicines that contain vitamins, minerals, antioxidants and phytonutrients that help with the body's maintenance and development as well as resist disease. They also offer a wide range of taste, smell, appearance and texture. Fruits are packed with many nutrients which are essential for the daily upkeep of the body, nevertheless, they are only available when they are in season and because of ripening can get spoilt quickly (Joy \& Abraham, 2013). Fruits can be eaten raw or made as a juice, squashes, jams and they can be preserved. In previous years when there were no refrigerators, fruits that were harvested in season were turned into homemade jams and stored during winter or given out as a gift (Plunkett, 2006).

Nowadays, jams are readily available for sale at most grocery stores, however, they do not have the same wholesome goodness or nutritional value as the homemade ones because they contain preservatives and have a contrived taste. According to Joy and Abraham (2013), fruit preservation is the process of treating and handling food to stop or slow down fruit spoilage, loss of quality, edibility or nutritional value and thus allow for longer fruit storage. Chopped or crushed fruits can be used to make jam by adding sugar to make a mixture which is then round up when placed on a spoon. Water is heated together with the fruits and sugar is added to activate the pectin in the fruit (Bastin, 2004). The mixture is then put into containers and sealed. The way jam is prepared only came into existence in the 19th century. It took a cheap and reliable source of sugar from the West Indies to make jams affordable. Sugar was considered a spice then and as such the price was so expensive that only the rich in Europe could afford to purchase it. Therefore, preserves made from sugar were too treasured so it could not be spread thickly on toast so instead they were eaten as "spoon sweets". It was distributed on delicate silver spoons filled with a great quantity of fruit preserves. Such treats were being offered in the Middle East and Eastern Europe along with a glass of water to cool you off. In European the first sugar preserves that were made didn't make use of sugar but honey was used instead. According to Leon (2011) the earliest fruit preserves were made by mixing the soft moist part of a fruit that was pounded to a pulp with honey that was dried in the sun which created a texture more like that of a jellied sweet.

Star fruit, Averrhoa Carambola is a small, bushy evergreen tree that grows very well under hot, humid, tropical conditions. It is called star fruit because when you cut crosswise into the fruit, it reveals a perfect star shape. The plant bears small lilac color, bell-shaped flowers in clusters, which subsequently develop into oblong shaped fruits with characteristic five angled edges (sides or ribs) that appear like a starfish when it is cut cross sectional. The fruit which are both sweet and sour varieties begin to yield under cultivable orchards, and can be harvested only when the plant reaches about 3-4 years old. Carambola fruit can be light-green to yellow in color and has an attractive smooth waxy surface and weighs about 70-130g. The flesh inside is crispy, has a juicy pulp and can either be very sweet or very sour depending upon the type of plant and species as well as the concentrated amount of oxalic acid. In some types, there are 2-5 tiny edible seeds found at the center of each angled cavity (Sonam, 2015). The fruit is completely edible, including the skin and is a good source of Vitamin C and dietary fiber (Mansfield City Schools, 2012). 


\subsection{Statement of the Problem}

Fruits are highly perishable items which needs processing to make it durable. The shelf life of star fruit is one week depending on temperature and humidity. Once ripe, it should be eaten within two or three days (Bastin, 2004). Star fruit just like any fruit do not last forever, they can be kept under room temperature for two to five days until ripe, one to two weeks once it is ripe in the refrigerator and ten to twelve months in the freezer. According to Joy and Abraham (2013), fruit preservation is the process of treating and handling food to stop or slow down spoilage but allows for the fruit to be stored over a longer period of time. Using fruit to make jam as a method of preservation involves boiling, adding sugar and sealing, yet still maintains nutritional value, texture and flavor. There are a number of varieties of jams on the market in Ghana today which consumers are already aware of. Some of these jams are Apricot jam, raspberry jam, strawberry jam, pineapple jam. Star fruit has many health benefit which many people are not aware of, and a way of creating this awareness of the health benefits, its importance and usefulness is to add value to the fruit through varied usage methods. Star fruit is usually either eaten as a fruit, used as juice and as a smoothie, however it is not used to produce jam. Among the wide variety of jams found in Ghana, star fruit jam is not one of them. Due to its high perishability rate when it is in season as a means to avoid spoiling and going to waste the researcher decided to use star fruit to make jam to add to the variety of jams on the Ghanaian market.

\subsection{Research Question}

The questions of interest to the researcher were;

1). Will it be possible to use star fruit to produce jam?

2). What was the taste, aroma, flavor, color appearance and after taste of the jam be?

3). Will the star fruit jam be accepted by consumers to other fruit jams?

4). Can consumers be encouraged to consume star fruit jam?

\subsection{Objectives of the Study}

The objectives of the study were to;

1). Find out if star fruit can be used to produce jam.

2). Assess the taste, aroma, flavor, color, appearance and aftertaste of the star fruit jam.

3). Examine if the star fruit jam will be accepted by customers.

4). Evaluate if customers can be encouraged to patronize the jam.

\section{Background Literature}

\subsection{Overview of Star Fruit}

Star fruit is known scientifically as Averrhoa Carambola (in some parts of the world) and Kamrakh (in India) - is native to Sri Lanka but it is grown throughout much of Asia, Australia 
and New Zealand. Being a well-adapted subtropical tree, it is also grown in Mexico, the Caribbean, Hawaii, and parts of Florida and California as well as all over the world. This star-shaped tropical fruit is cultivated for its fruits and they come in two different varieties: unsoured and soured. During the summer and autumn months the unsoured fruit can be found and are harvested, the soured fruit however is harvested at the end of summer to the middle of winter. Star fruit is a small, bushy evergreen tree that grows which flourish ideally in hot, humid and tropical conditions. It is a deciduous tree known distinctly for its long ellipsoidal, or five-pointed fruit. There are mainly two different kinds of star fruit: Sweet and Sour. The tree itself can reach up to 20 or 30 feet tall when mature. The leaves are oval in shape and then taper to a fine point. They have a bright green color to them. (Leon, 2011). The flowers are about a half-inch in diameter and have a purple-pink color to them. After 3-4 years the plants are farmed productively, and the unsoured and the soured fruits can be harvested. The star fruit plant can be identified by its small lilac colored, bell-shaped flowers which can be found in clusters. It then grows into an elongated shape with parallel sides that has five angled edges which can pass off as a starfish when cut cross sectional. Weighing approximately $70-130 \mathrm{~g}$, the fruit is characterized by a light green slightly yellowish color and a smooth surface that is wax-like. The flesh on the inside contains a lot of juice and can either be midly sugary or sweet or extremely acidic or sour based on the cultivar type and concentrated amount of oxalic acid. In some instances, one can find 2 - 5 small yet eatable seeds at the center of each slanted cavity. When cut in half, the fruit has a star-shape, giving it the name, 'Star Fruit.' The fruit is known for its heavy citrus fragrance when completely ripe. The fruit color can range from a pale white to a golden yellow. Star fruit is anywhere from 3 - 8 inches long and around 2 - 4 inches across. The skin has a waxy look to it with heavy ribbing at the star points. Some cultivars are seedless while others contain about 12 quarter-inch brown seeds. Carambola is available in great quantities in the East, but it is not widely sought after in other parts of the world, especially in the west. Star fruit is a commodity that is not widely known but is rich in nutrients and has a wide range of uses such as when unripened as a vegetable, in a salad or as a desert when it is fully ripe. Other uses include as a star fruit juice as with most fruits, as an ingredient or on its own in a smoothie or shake, or eaten raw as a fruit. To get the maximum amount of nutrients for your body it is best to eat it fresh within 3-4 days otherwise there would be reduction in its nutritional values. It should also be stored where there is minimum light and cold and should be cut only when it is ready to be eaten (Mercola, 1996).

\subsection{Nutritional Value of Star Fruit}

Though it is scarcely known in many parts of the world, the star fruit is a unique fruit which is imbued with many nutritional benefits. Table 2.1 gives a summary of the commonly known nutritional values of an average-size star fruit. 
Table 1. Nutritional value of star fruit

\begin{tabular}{|c|c|}
\hline Nutrient & Amount \\
\hline Energy & $128 \mathrm{kj}(31 \mathrm{kcal})$ \\
\hline Carbohydrate & $6.73 \mathrm{~g}$ \\
\hline Dietary fibre & $2.8 \mathrm{~g}$ \\
\hline Protein & $1.04 \mathrm{~g}$ \\
\hline Vitamin C & $34.4 \mathrm{~g}$ \\
\hline Vitamin E & $0.15 \mathrm{mg}$ \\
\hline Iron & $0.08 \mathrm{mg}$ \\
\hline Fat & $0.33 \mathrm{~g}$ \\
\hline Sugars & $3.98 \mathrm{~g}$ \\
\hline Zinc & $0.12 \mathrm{mg}$ \\
\hline Calcium & $3 \mathrm{mg}$ \\
\hline Vitamin B & $60.017 \mathrm{mg}$ \\
\hline Choline & $7.6 \mathrm{mg}$ \\
\hline Sodium & $2 \mathrm{~g}$ \\
\hline Potassium & $133 \mathrm{mg}$ \\
\hline
\end{tabular}

Source: Sonam, 2015.

\subsection{Health Benefits of Star Fruit}

According to Singh, Sharma, and Goyal (2014), the star fruit has many medicinal properties and is used widely all over the world for hangovers and sunburns. It also works very well to cure coughs, fever, ulcers and sore throats and is said to fight against diabetes. Not only the fruit itself that combats ailments but other components such as the leaves also help with stomach ulcers, skin inflammations and boils as well as improving digestion. The flower is a good remedy for coughs in children. The fruit is filled with fibre and only has 31 calories making it a good choice for those trying to lose weight. Sonam (2015), reported that it only contains $9.5 \mathrm{~g}$ of carbohydrates per serving, $2.5 \mathrm{~g}$ of dietary fibre, $3 \%$ of the recommended daily allowance for carbohydrates and $10 \%$ of the recommended daily allowance for dietary fibre. She also indicated that they are also full of antioxidants and flavonoids. Furthermore the star fruit is a good source of antioxidants and vitamin $\mathrm{C}$ which delays the natural ageing process. Once ingested, the presence of the fruit allows other nutrients to move freely in the body. Vitamin B complex which is needed for hair growth as well as keeping the hair shiny, healthy, strong and preventing hair loss is copiously abundant in star fruit. She further, recommended that the fruit can be used straight on skin that is oily or for people who have a problem with acne as a face mask since it is good for the skin in both ways. The International Journal on Food Science and Nutrition (2014) indicated that Along with vitamins A, B and C, that help maintain the metabolism of the body regularly and sound, star fruit also contains thiamine, riboflavin, and niacin in small amounts. It is a good source of vitamin B9 (folic acid), which assists the body to decrease the rate of heart related diseases and stroke. It has a very small amount of all essential minerals most especially copper (14\% of Recommended Dietary Allowance (RDA) 
in one medium sized fruit) and is also said to decrease cholesterol levels and cure sore eyes. It purifies the blood and makes the skin glow. Star fruit comprises of zinc which is known to decrease acne break outs and is very good for people of all ages because of its antimicrobial properties (Mercola, 1996). Finally, Leon (2011) referring to the star fruit as a 'magic' fruit, indicated that lactating mothers can eat the fruit because it helps increase the production and flow of milk. When the leaves and roots are boiled together the water soluble substances can be extracted which can heal headaches, ringworm and chickenpox. A quick remedy for nausea and indigestion would be to eat half a piece of the fruit every three hours.

Adversely, Sonam (2015) advised that it is not recommended for people with renal/kidney problems due to the high concentration of oxalic acid. Due to its interference it can cause malabsorption and slow down metabolism of various natural minerals such as calcium, magnesium, etc., scientists consider the fruit an anti-nutrient compound. Also, she stated that just like grapefruit, the star fruit can impede the effect of medication taken for other sicknesses and that one should consult his or her doctor if on medication.

\subsection{Overview of Jam and Its Preparation}

Jams are a food commodity developed using a minimum of products formulated from a minimum of $40 \%$ fruit and an ultimate soluble solid content of $45^{\circ}$ Brix sometimes through the addition of a few food additives such as citrate, gelling agents and pectic acid. They are made from crushed and or shredded fruit with sugar by boiling until the mixture becomes thicker and forms a round ball on a spoon (Bastin, 2004).

\subsubsection{Types of Jam}

There are no distinctive differences in jams. However, since they are made of different fruits the perceived difference could be as a result of the kind of fruit that it was made of. People without the requisite food production knowledge tend to harbor the perception that jellies, jams and preserves are different types of jam. Jam can be made from the following fruit pineapple, orange, apricot, strawberry, grapes, apple and many more. A survey conducted each year between February 2010 to March 2014 among 24,000 American adults on the types or flavors of jam eaten in their households indicated households ate strawberry jams the most in 2012 (Beauman, 2005). Also, according to McWilliams (2005), jam and preserves are fruits preserved by cooking with sugar and pectic acid (a water soluble colloidal carbohydrate that occur in ripe fruit) which when water and sugar together with the fruit are heated forms a gel and is also responsible for the thickness of jams, jellies and preserves. The difference between jam, jelly and preserves is the form which the fruit is in. With regard to jelly the fruit is a juice form, whiles in jam it is either shredded or chopped (which makes it less rigid than jelly). However, in preserves the fruit are placed in a syrup or jam in chunks.

\subsubsection{Jam Preparation}

In order to ensure the proper production of jam there are laid down procedures that have to be followed. The following are some of the common procedures or guidelines that are used in preparing jams: 


\subsubsection{Steps in Jam Making}

1). Check if fruits are firm and not over ripe. Use fruits that are not fully or slightly developed, mature or ripe since it contains more pectin, as this will make it easier for the jam to set. Unripe fruit does not have the same degree of flavor extremely delicious and acceptable jam needs.

2). Wash fruit under clean running water. Fruit can be washed with salt solution to get rid of any germs and grate them into pieces with gloves being worn.

3). Weighed sugar $(750 \mathrm{~g})$ and add $(300 \mathrm{ml})$ water to the sugar.

4). Put sugar and water mixture on fire. The sugar must dissolve well before allowing the mixture to come to a boiling point. Allow to boil to a light gold caramel color.

5). Add the grated fruits $(1 \mathrm{~kg})$ to the sugar mixture and allow to cook under gentle heat for 20 minutes. Bring the jam to a boiling point as quickly as possible to ensure that the jam reaches a point where it will solidify.

6). Remove jam from fire and perform cold test. To know the end point of the jam, test for the setting point of the jam. A well set jam transforms into a concentrated, thickened, viscous, uniformed, homogeneous clear form.

7). Pour jam into clean sterilized bottles and cover with a tight lid.

8). Jam must cool a little before applying the lid. Make sure no content of the jam gets on the rim of the jar. It can greatly add to friction after the lid is on. It actually makes the whole process unreliable. The jam might prevent a seal from forming or it might harden and make the lid difficult to remove. Always the rim of the jar must be clean before using it to cover the jam.

9). Store in a cool, dark, dry place between fifty to seventy degrees Fahrenheit (Egan, 2006).

\subsubsection{Faults in Jam Preparation}

Though there are no strict guidelines regarding the production of jams, there are going to be mistakes if the right procedures are not followed. The following are some of the mistakes or faults that are sometimes observed in jam preparation. The jam being too softened, due to a disproportionate amount of sugar, acid and fruit. A large batch of the mixture which can cause the jam to be undercooked will also result in a jam which is too soft. Another problem is jam that weeps. This happens as a result of a large amount of acid in the fruit or when too much acid from lemon juice is added. The place where jam is stored may also contribute to the jam weeping. This can happen when the place is too warm or when there is a drastic change in temperature. Naturally fruits are prone to fermentation and this can also be a problem when the amount of sugar is too small or the jar that it is placed in is not sealed properly. To prevent fermentation and to ensure proper sealing, the boiling water process needs to be used. The top of the container can at times make the jam dark. The boiling water method is a process whereby the jars are placed in a pot filled with water and boiled. By applying this process fermentation in foods with a high acid content is lowered thereby extending its shelf life. Fruits that are red in color have a tendency of losing their color over a time. Pouring the jam too slowly into the jar can allow air bubbles to form and leaving the mixture after cooking to stand for a long time 
before pouring it into a jar can also make the jam cloudy. When the jam is not properly sealed or airtight, mould can grow on it. Mould growth on jam should be avoided because consumers will not buy mouldy jam and also mould growth will cause severe food poisoning. Although initially thought of as being non toxic and that just taking off the mould and eating the rest of the jam was acceptable, research has shown that mould indeed is toxic in our bodies and should be avoided altogether. Mouldy jam should be thrown away entirely and the most advisable way to avoid mould growth on jam is to pour the jam whilst it is still hot in a hot pre-sterilised canning jar. The can should not be filed to the brim but leave a fourth of an inch off the top of the jar. It should then be sealed with a pre-treated two piece lids and the boiling water process should be applied for the recommended time (Singh-Ackbarali \& Maharaj, 2014).

\subsection{Pectin in Fruits}

Pectin is a colloidal carbohydrate found in fruits. When sugar is added, the pectin in fruit or commercial pectin separates and forms insoluble fibers. Adding another acid, such as lemon juice or citric acid, aids the fruit separate as a fine suspension of solid particles. The insoluble fibers produce a mesh-like structure that traps the juice from the fruit or other liquid, just like a sponge absorbs water. This modifies the juice into a gel. Recipes without added pectin rely on the natural pectin in the fruit to transform into a gel. Due to their high levels of pectin tart apples, sour blackberries, cranberries, currants, gooseberries, concord grapes, soft plums, and quinces work well in recipes that do not require for commercial pectin to be added. Slightly under-ripe fruit contains more pectin than ripe fruit, however, overripe fruit may not contain enough pectin to form a gel and would therefore require the addition of commercial pectin. A general recipe that is mostly used is adding one part under-ripe fruit to two parts fully ripe fruit so that the best gel and flavour can be formed. The USDA canning guide recommends at least one fourth of the fruit should be under-ripe. Recipes without added pectin use the natural pectin that is found in slightly under ripe fruits to form a gel. Fruits such as apricots, blueberries, cherries, peaches, pineapple, rhubarb, and strawberries naturally have a small amount of pectin in them so the use of commercial pectin is the only way that a gel can be formed. Alternatively fruits which contain a higher amount of pectin can be intermixed with one's low in pectin to form a gel therefore creating new jams. When the commercial pectin is used the cooking time is reduced because the introduction of heat makes the pectin water soluble. The fruit must be heated in order for jelling to take place, but care should be taken not to cook it for a long time and at high heat otherwise pectin which is easily destroyed by heat will lead to the formation of a poor gel. When making large batches of jam where the recipe needs to be doubled the cooking time needs to be extended. The increase in the time allows the mixture to boil and this can result in the formation of a soft gel. Commercial pectin can be added to any fruit, including fruits that have a high pectin content. Adding too much pectin will result in a tough, rubbery consistency, which is difficult to spread. Following the recipe guide step by step that comes with the commercial pectin will help annihilate this difficulty (Bastin, 2004).

\subsection{Overview of Sensory Analysis or Evaluation}

For today's consumers, the most essential factor thought of when choosing a food product to eat is the commodity's tastiness- or eating attributes, and other performance factors, such as 
nutrition and its benefits are subsidary (Meiselman \& MacFie, 1996; Lawless \& Heymann, 1998). In order for the giants in the food and beverage industry, to be superior in the market or successful, they should make sure that the quality of food is aattractive and appetizing or specifically that the eating quality properties of; smell, taste, aftertaste, texture and appearance is fit for the consumer so that they desire for more. It can be agreed that qualities that affect food or qualities that consumers desire or consider as the most important are based on what they understand or rate according to the level of preference of factor, or the lack of unsuitable attributes which when perceived by the consumer's sensory faculty then a worthy technique of measuring attributes of food such as conducting a sensory evaluation or analysis should be applied.

According to Sidel and Stone (1993), sensory evaluation or analysis has been termed as a field of study utilized to stimulate, determine, examine and explain reactions to products as realized through the sensory factors such as of visual image (sight), scent, touch sensation, taste sensation and sense of hearing. Many studies (McWilliams, 2005; Meilgaard, Civille, \& Carr, 1999; Jamesen, 1998) have shown that consumers' perception of the sensory attributes of food tend to go by the undermentioned:

1) Appearance - visual image Color

Size \& shape (form)

Outward attributes

Internal appearance

Clearness

Carbonation

2) Odour /Scent/Smell

Odour of a food product is sensed when food substances register in the nasal consonant and are detected by the olfactory system Volatility - related to the temperature of the food and the nature of the compounds

3) Flavour: Sensory properties that come about as a result of gustatory sensation and smell comprises fragrance - feelings caused by substrate substances released from a product in the mouth (lemon, mint, buttery) taste - perceptions caused by dissolved components in the mouth (salty, sweet, sour, bitter) Chemical feeling factors - substances which are stimulated by the nerve endings in the soft membranes of the mouth and nasal cavity (spicy hot, cool, metallic). These comprise of factors that increase or decrease gustatory sensation.

4) Roughness or smoothness/ Mouth-feel an assessment of the detectors in the mouth aside from how it tastes and chemical feeling factor includes;

Viscosity - refers to the body, cohesiveness, gelatinousness and the liquid's fluidity when the force of gravity is enforced. These factors can also be measured correctly using objective methods. 


\section{Macrothink}

Global Journal of Educational Studies

ISSN 2377-3936

2016, Vol. 2, No. 2

Consistency -the ability of the property to hold together or retain its original shape and having a relatively high resistance to flow thereby making the solutions very thick and between a solid and a liquid.

Texture - sensory indication of the feel, roughness or smoothness or the internal composition of a food commodity (solids or semi-solids).

\section{Materials and Methods}

\subsection{Research Design}

Samples of the jams were given to respondents who comprised of 20 lecturers and 60 students from Takoradi Polytechnic to assess the flavor, taste, color appearance, texture, aroma and after-taste using a structured questionnaire. The data gathered was subjected to statistical analysis based on the objectives of the study using SPSS Statistics computer software version 17. The data was presented using tables, pie charts and barcharts. The star fruits were obtained from Market Circle, the largest and central market within the Sekondi- Takoradi Metropolis.

\subsection{Sample Collection}

To obtain the sample of the star fruit for the production of the jam, the whole bunch of fruits was put into two groups: under-ripped and ripped (fully or over-ripped). The slightly or under-ripped ones were sorted out for defective ones and the ones without defects were used to make the jam.

\subsection{Sampling Technique}

Purposive sampling was used to select Hospitality management department at Takoradi Polytechnic and convenience sampling was used to select the students and lecturers. A sample size of one hundred respondents was used.

\subsection{Data Collection Instrument}

The data collection instrument that was employed in the study was a questionnaire. The questionnaire consisted of both open and close-ended questions. Respondents were required to indicated indicate with regard to preference whether the samples were very good, good, poor and very poor.

\subsection{Product Development or Product Preparation}

The production of the jam begun just after the needed fruits had been selected. The general idea behind making jam is to add fruit, pectin, acid and sugar apportioned in the right quantity.

The following is an adopted process through which the jam was prepared and is presented in Figure 3.1 as adopted from Egan, (2006).

\subsubsection{Basic Ingredient Used to Prepare the Jam}

Fresh under ripped star fruit and pineapple

Refined sugar 


\section{Macrothink}

\subsubsection{Equipment Used to Prepare the Jam}

Weighing scale, chopping board, plastic bowls, knife, plastic plates, wooden spoons, large stainless saucepans and a grater.

\subsubsection{Product Preparation}

The following ratios were used to prepare the samples; Sample A 100\% Pineapple, Sample B $100 \%$ Star fruit and Sample C 50\% Star fruit and 50\% Pineapple.

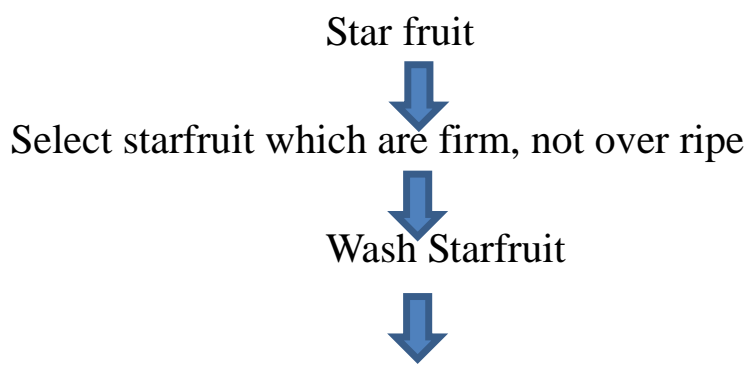

Grate the Starfruit

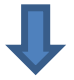

Weigh 750 grams of sugar and 1 kilogram Grated Starfruit

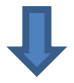

Measure $300 \mathrm{ml}$ of water, add the water $(300 \mathrm{ml})$ to the sugar $(750 \mathrm{~g})$

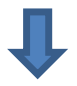

Put sugar and water mixture on fire. Allow to boil to a light gold caramelize colour

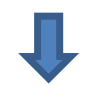

Add $1 \mathrm{~kg}$ grated fruit to the sugar mixture and allow to cook under gentle heat for $30 \mathrm{mins}$

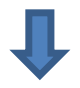

Remove jam from fire and perform cold test

Allow to cool and pour into sterilized bottles

Figure 1. Flow chart of the production of jam 


\section{Mll Macrothink}

\section{Results and Discussions}

\subsection{Demographic Characteristics}

Table 2. Demographic characteristics

\begin{tabular}{|c|c|c|}
\hline Response & Frequency & Percentage \\
\hline Gender & 42 & 43 \\
Male & 56 & 57 \\
Female & 98 & 100 \\
Total & & \\
\hline Age group & 32 & 33 \\
$18-23$ & 48 & 49 \\
$24-29$ & 8 & 8 \\
$30-35$ & 10 & 10 \\
$36-41$ & 98 & 100 \\
Total & & \\
Occupation & 70 & 72 \\
Student & 10 & 10 \\
Lecturer & 18 & 18 \\
Non-teaching staff & 98 & 100 \\
Total & & \\
\hline
\end{tabular}

Source: Field Work, June 2015.

Table 2 is a presentation of the demographic information of the respondents. More than half of the respondents $(57 \%)$ in were female and $43 \%$ were male. Forty-nine percent were between the ages of 24 - 29 years of age, $33 \%$ were 18 - 23 years, and only $8 \%$ were between the ages of 30 - 35 years. Majority of the respondents (72\%) were students. Eighteen percent were non-teaching staff, only $10 \%$ were lecturers.

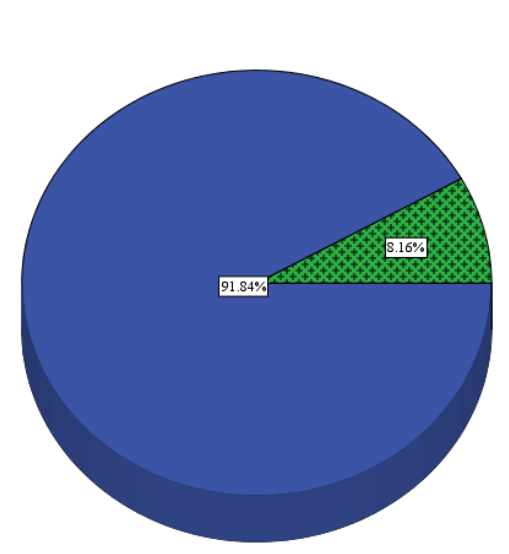

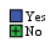

Figure 2. Respondents' tasting of jam before

Source: Field Work, June 2015. 


\section{$\triangle 1$ Macrothink}

Global Journal of Educational Studies

ISSN 2377-3936

2016, Vol. 2, No. 2

It can be seen in Figure 2 that when respondents were asked if they had tasted jam before about $92 \%$ said "Yes" and only 10\% said "No". This implies that the respondents were not new to the consumption of jam.

Table 3. Types of jam ever tasted

\begin{tabular}{|c|c|c|}
\hline Response & Frequency & Percentage \\
\hline Strawberry & 84 & 93 \\
\hline Pineapple & 50 & 56 \\
\hline Apricot & 14 & 16 \\
\hline Orange & 28 & 31 \\
\hline Apple & 14 & 16 \\
\hline Other & 30 & 33 \\
\hline Total & & $\mathbf{1 0 0}$ \\
\hline
\end{tabular}

Source: Field Work, June 2015.

Most of the respondents (93\%) indicated that they had tasted strawberry jam, 56\% had tasted pineapple jam, 16\% had tasted apricot and apple jams respectively. It is interesting to note that strawberries are not grown in Ghana and as such strawberry jam is imported. However, pineapples which are grown in Ghana was the second most tasted jam. This can be seen in table 3. According to Beauman (2005) the results of a survey conducted from February 2010 to March 2014 among 24,000 American adults each year on the most eaten flavors of jams by the people living in their household was strawberry jam. Coincidentally the same was found in this research.

\subsection{Have You Seen Star Fruit Before?}

When respondents were asked if they had seen a stair fruit before, 62\% said "Yes" and 38\% said "No". This suggests that the star fruits were not scarce among the respondents as it is believed.

\subsection{Consumption of Star Fruit}

Majority of the respondents $(55 \%)$ indicated that they had eaten a star fruit before, whilst $45 \%$ reported that they had never eaten one before. This also implies that the consumption of star fruit is not as rare among the respondents. According to Sonam, (2015) the fruit is scarcely known in many parts of the world, but star fruit is a unique fruit which is imbued with many nutritional benefits. This is not in line with this research because majority of the respondents had eaten the fruit before; however, the difference between those who had eaten star fruit before and those who had not was not the great.

\subsection{Ways of Consuming Star Fruit}

Majority of the respondents (75\%) said they ate it raw, whilst $25 \%$ said they had blended it and drank it as juice. 


\section{Macrothink}

\subsection{Knowledge of Any Star Fruit Product(s)}

On the notion on whether respondents had any knowledge of star fruit products, almost all the respondents $(97 \%)$ indicated that they did not know of other food products made from star fruit only (3\%) said they had seen a starfruit product before.

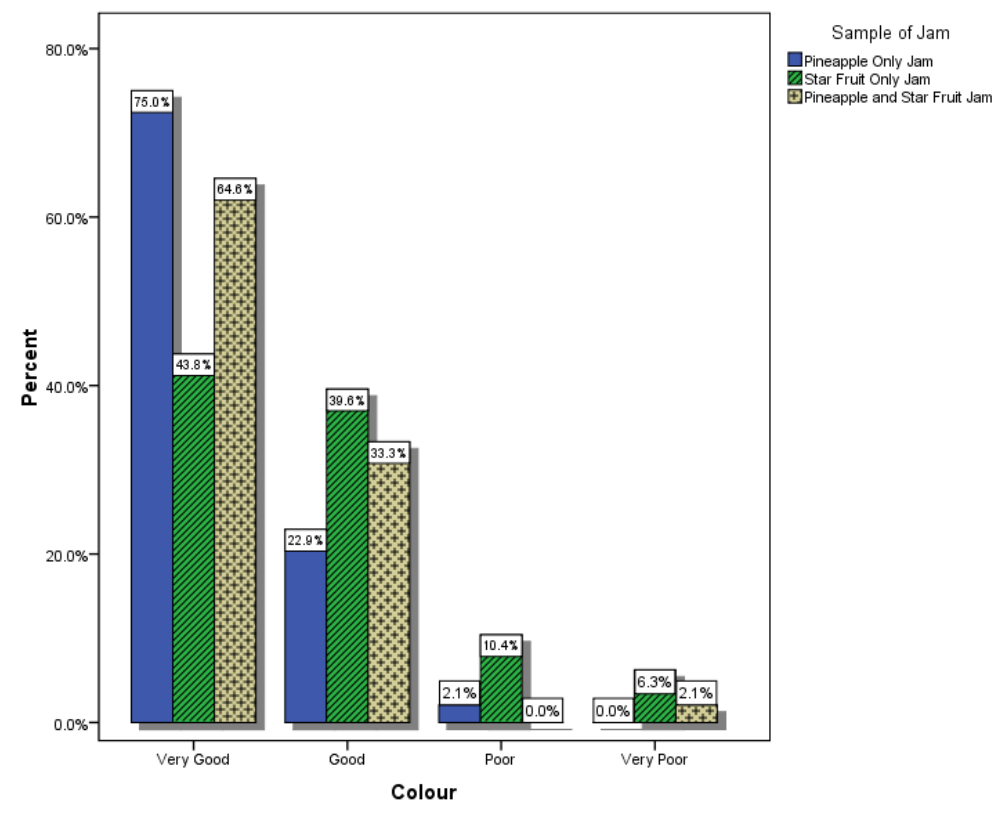

Figure 3. Respondents' assessment of jam products' color

Source: Field Work, June 2015.

In Figure 3 generally the colors of pineapple jam, star fruit jam and pineapple and star fruit jam were regarded as good. However, the color of the star fruit jam was considered not as good as the pineapple jam and the pineapple and star fruit jam. For pineapple jam, majority of the respondents $(75 \%)$ mentioned that it was very good and about $65 \%$ for the pineapple and star fruit jam. However, $40 \%$ mentioned that the star fruit jam was good. Ten percent mentioned that star fruit jam was poor and six percent said it was very poor. Only two percent said that pineapple and star fruit jam was very poor and none said the pineapple jam was poor. 


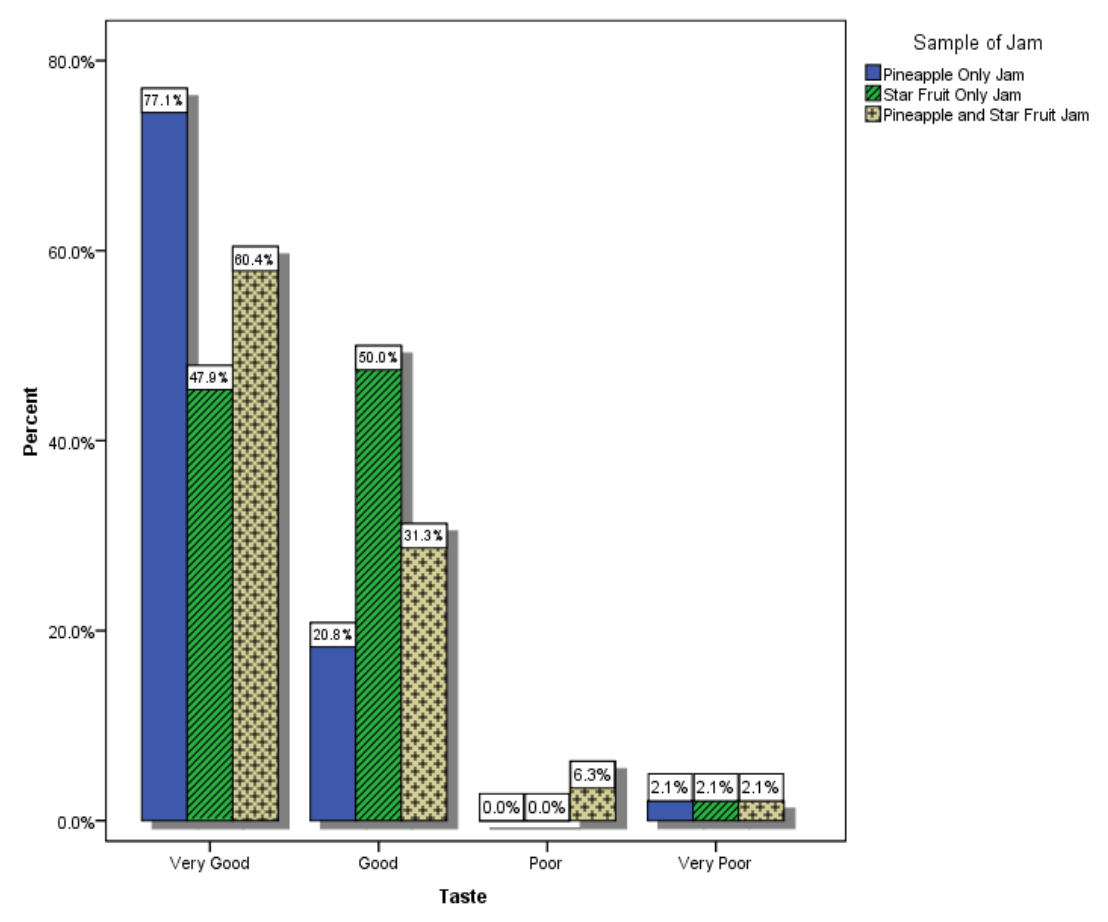

Figure 4. Respondents' assessment of jam products' taste

Source: Field Work, June 2015.

Seventy-seven percent of the respondents indicated that the taste of the pineapple jam was very good. Only $40 \%$ said the star fruit jam was very good. However, half of the respondents $(50 \%)$ stated that the taste of the star fruit jam was good, $21 \%$ said the pineapple jam was good. None of the respondents said that the pineapple and star fruit jam was poor but there was an equal number (2\%) that said all the jams were very poor (Figure 4).

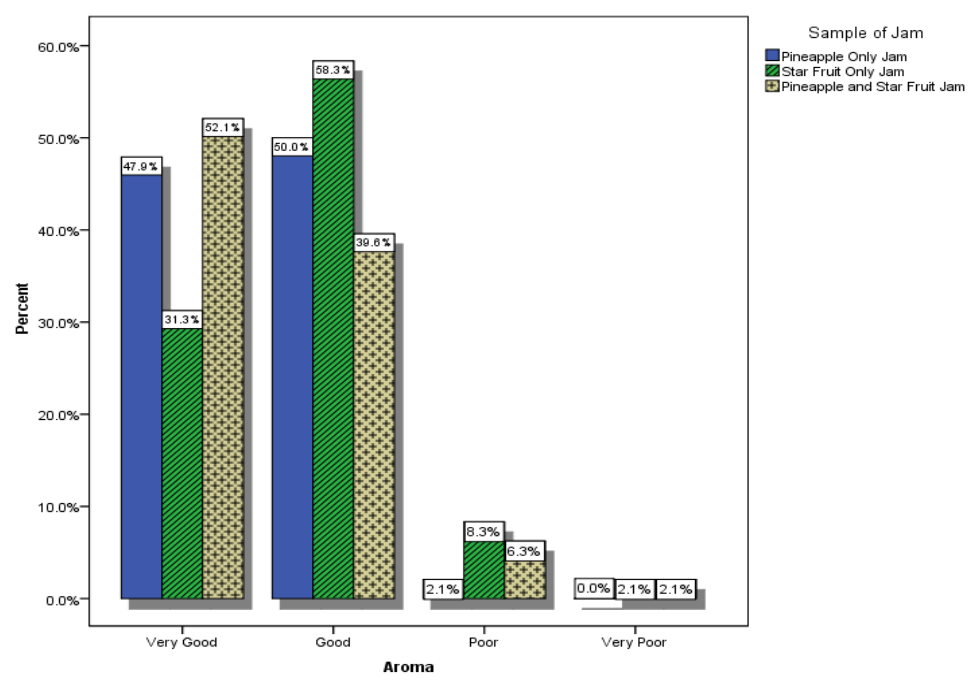

Figure 5. Respondents' assessment of jam products' aroma

Source: Field Work, June 2015. 


\section{Macrothink}

Global Journal of Educational Studies

ISSN 2377-3936

2016, Vol. 2, No. 2

In Figure 5 the aroma of the starfruit jam was considered to be good by majority of the respondents (58\%), 52\% said the starfruit and pineapple jam was very good, $31 \%$ indicated that the aroma of the star fruit jam was very good. Eight percent indicated that the aroma of the pineapple jam was poor. Six percent said pineapple and starfruit jam was poor. None of the respondents said the aroma of the pineapple jam was very poor. However, an equal number said the aroma of the star fruit and pineapple and starfruit jam was very poor.

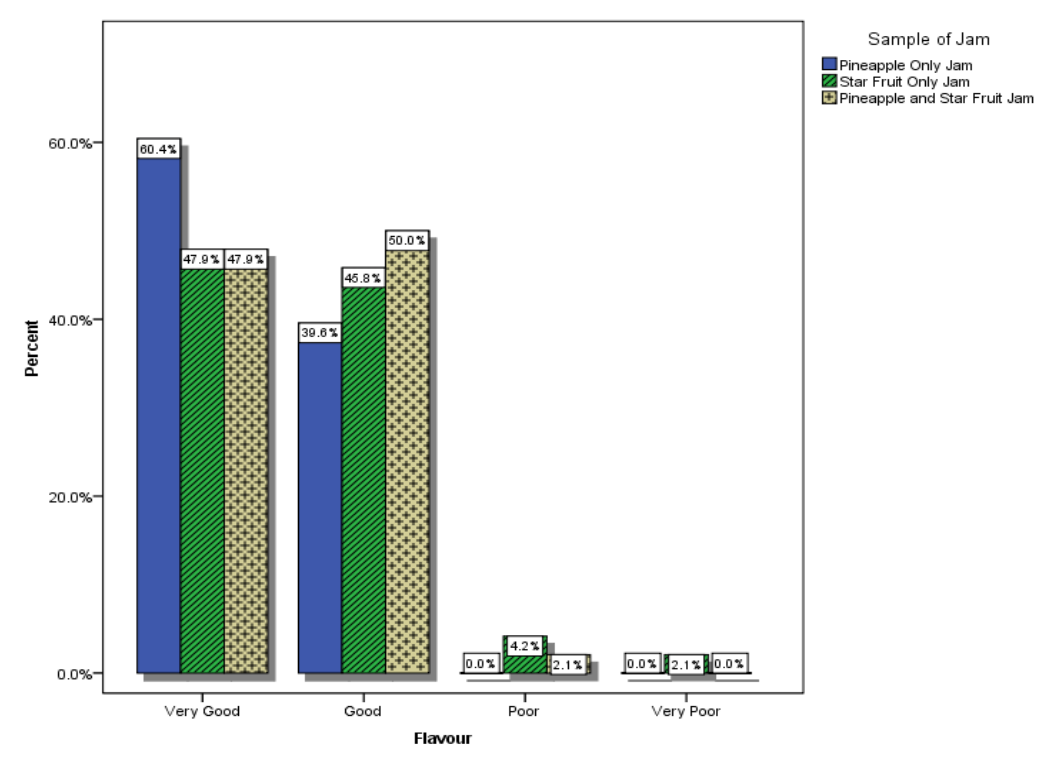

Figure 6. Respondents' assessment of jam products' flavor

Source: Field Work, June 2015.

The figure above shows that most of the respondents $(60 \%)$ stated that, the flavor of the pineapple jam was very good. An equal number of respondents $(48 \%)$ stated that the flavor of the star fruit jam and the pineapple and star fruit jam was very good. Exactly half of the respondents $(50 \%)$ mentioned that the pineapple and star fruit jam had good flavor with about $40 \%$ of them saying the pineapple jam's flavor was good. 


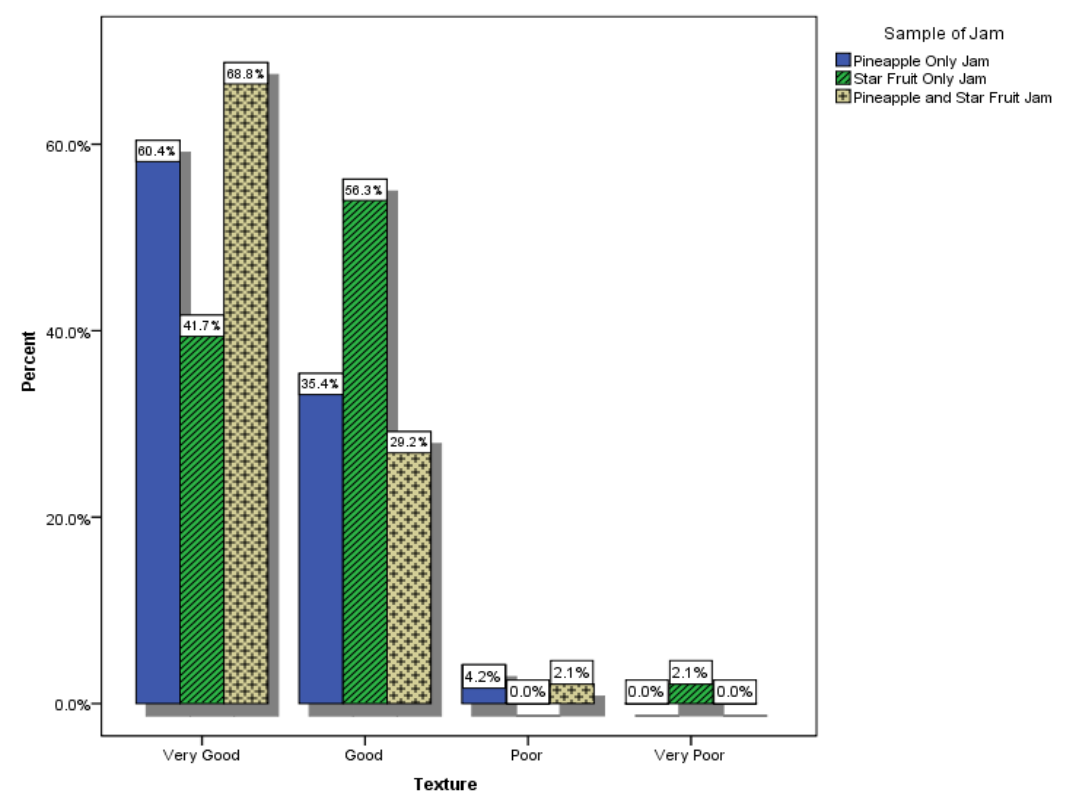

Figure 7. Respondents' assessment of jam products' texture

Source: Field Work, June 2015.

Almost all the respondents generally gave the indication that the textures of all the different types of jam were good. Sixty-nine percent said that the textures of the pineapple and star fruit jam and the pineapple jam $(60 \%)$ were very good. Fifty-six percent mentioned that the texture of the star fruit jam was good. The figure also shows that about $2 \%$ of the respondents said the star fruit jam's flavor was very poor though none said it was poor.

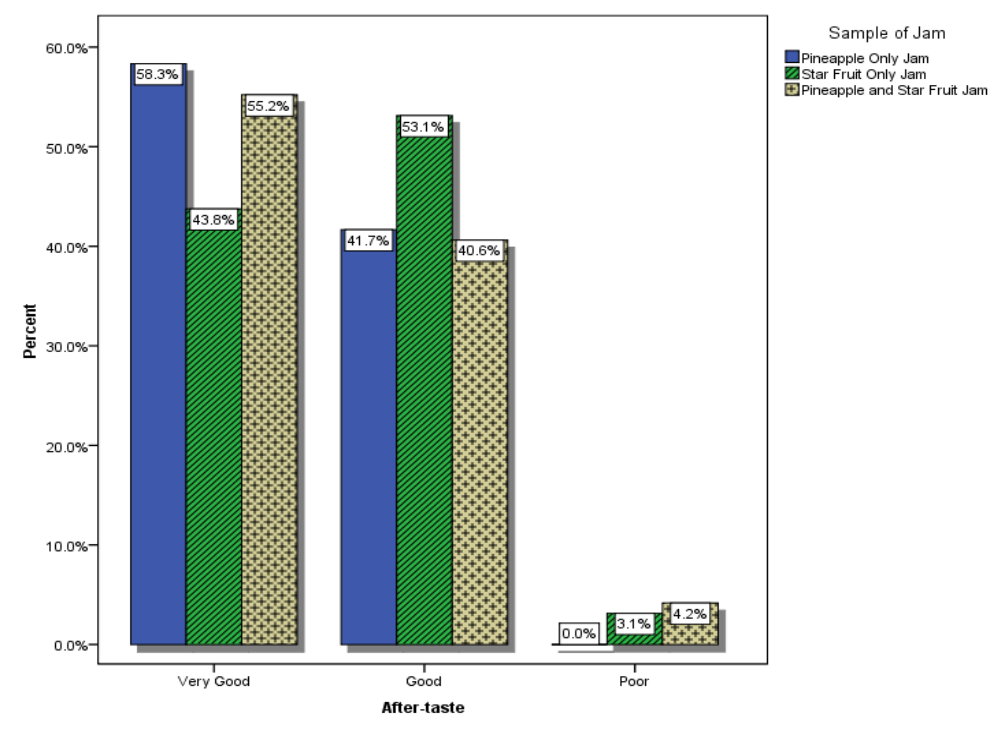

Figure 8. Respondents' assessment of jam products' after-taste

Source: Field Work, June 2015. 


\section{Macrothink}

Global Journal of Educational Studies

ISSN 2377-3936

2016, Vol. 2, No. 2

In Figure 8, more than half of the respondents $(58 \%)$ pointed out that the pineapple jam left a very good after-taste. About $44 \%$ of the respondents were also of the view that the star fruit jam had a very good after-taste. Fifty three percent indicated that the star fruit jam had a good after-taste, and a similar number of the respondents (42\%) indicated that the after-taste of the pineapple jam and the pineapple and star fruit jam (41\%) left a good aftertaste. Also, none of the respondents said the after-taste of the star fruit jam was either poor or very poor. About $3 \%$ as well as about $4 \%$ of the respondents indicated that the after-taste of the star fruit jam and the pineapple and star fruit jam were poor.

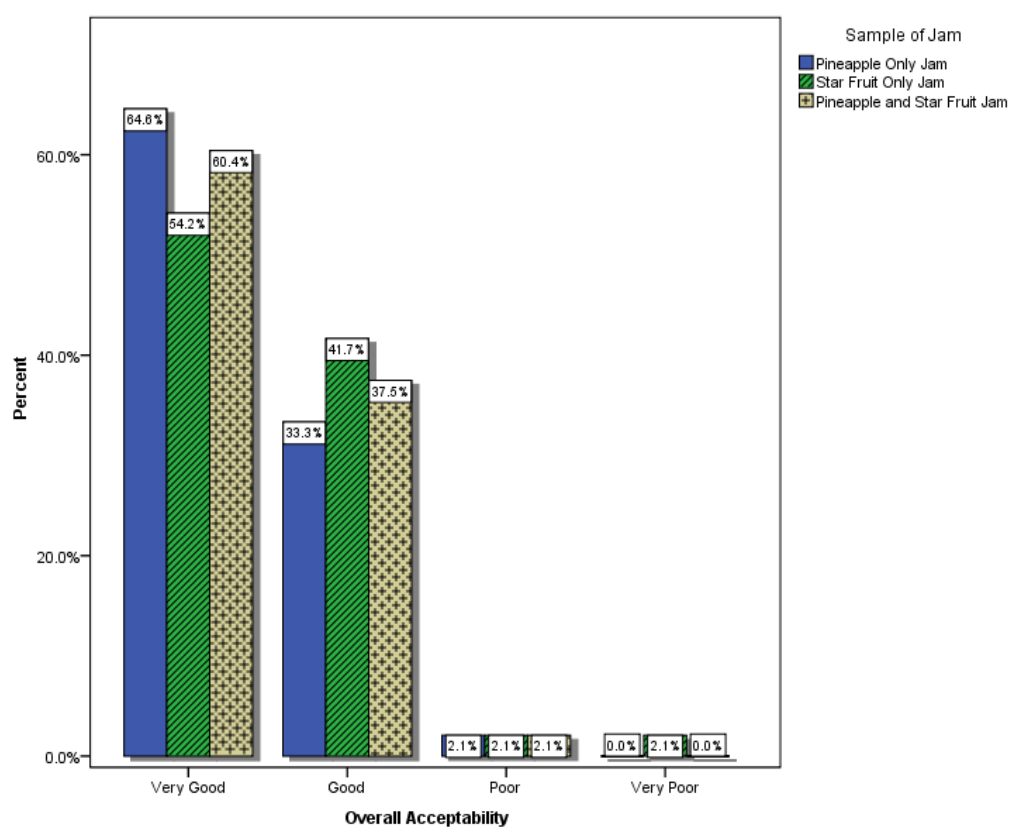

Figure 9. Respondents' assessment of jam products' overall acceptability

Source: Field Work, June 2015.

Majority of the respondents $(65 \%)$ indicated that the pineapple jam, pineapple and star fruit jam $(60 \%)$ and the starfruit jam (54\%) was very good. Also, a good number of the respondents $(42 \%)$ indicated that the overall acceptability of star fruit jam was good. An equal number two percent $(2 \%)$ of the respondents indicated that all the three (3) jams products were poor with two percent also saying that star fruit jam was very poor though none indicated the pineapple and star fruit jams' overall acceptability was very poor. 


\section{Macrothink}

Table 4. Preferred type of jam

\begin{tabular}{|c|c|c|}
\hline Response & Frequency & Percentage \\
\hline Pineapple jam & 46 & 37 \\
\hline Starfruit jam & 28 & 23 \\
\hline Pineapple and starfruit jam & 50 & 40 \\
\hline Total & & $\mathbf{1 0 0}$ \\
\hline
\end{tabular}

Source: Field Work, June 2015.

Most of the respondents (51\%) indicated that they preferred the pineapple and starfruit jam to the others, (47\%) also indicated that they preferred pineapple jam and 29\%s preferred the star fruit jam as seen in table 4 . This indicates that the respondents preferred the combination of the pineapple and star fruit jam to the star fruit only jam.

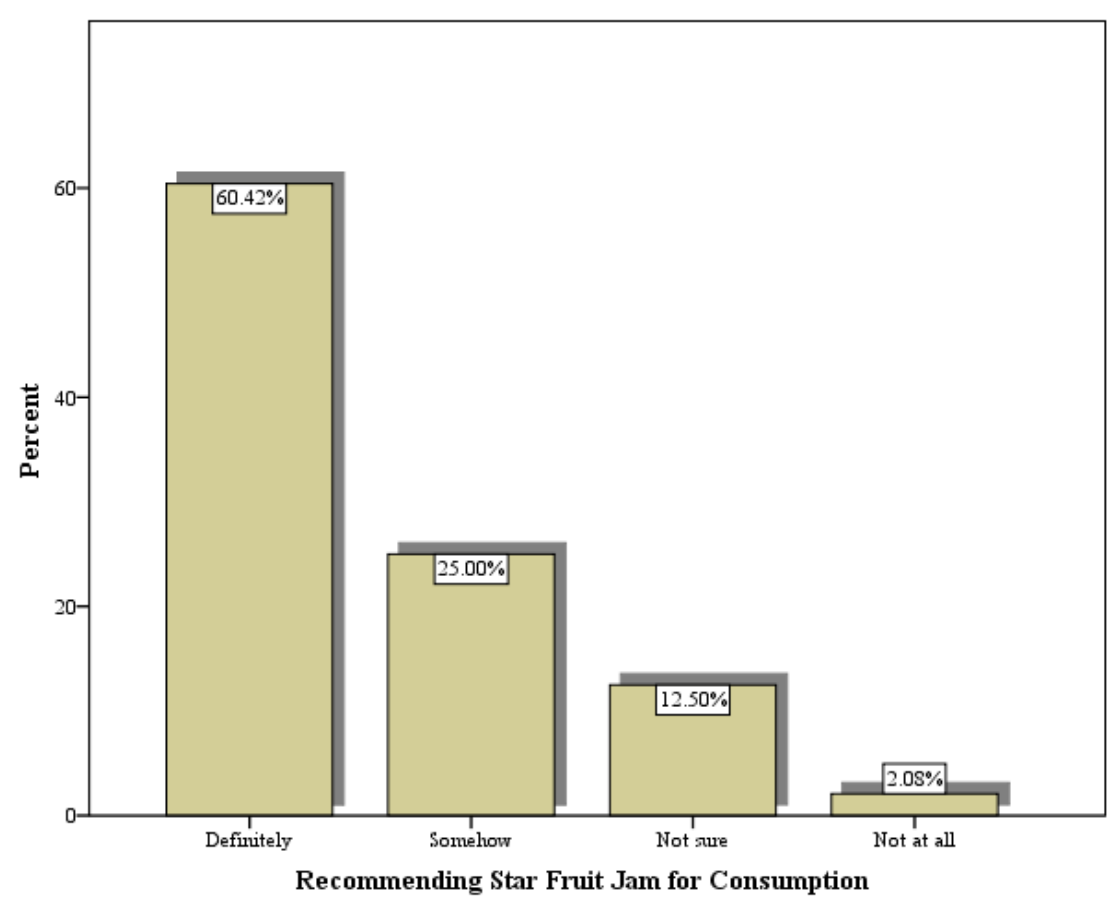

Figure 10. Respondents' recommendation of star fruit jam to friends and relatives

Source: Field Work, June 2015.

Most of the respondents (60\%) said they would definitely recommend the consumption of star fruit jam to their friends and relatives. A quarter (25\%) of the respondents said that they would somehow recommend the star fruit jam to others for consumption. About $13 \%$ of them indicated they were not sure they would recommend the jam to others whilst only $2 \%$ said 
they would not recommend it to others at all (Figure 10).

\section{Findings, Conclusions and Recommendations}

Starfruit can be used to produce jam. Most of the respondents were not new to the consumption of jam as most indicated they had tasted jam (specifically, strawberry and pineapple jams) before and they had seen and eaten starfruits before. They had consumed it by either eating them raw or blending them into juice and drinking it. Almost all the respondents indicated that they did not know of any other food product made from star fruits. Furthermore, the study found out that most of the respondents indicated that the sensory attributes (that is, the color, taste, aroma, flavor, texture, after-taste and overall acceptability) of the pineapple, star fruits and the pineapple and star fruit jams were generally very good. Finally, most of the respondents indicated that they preferred the pineapple jam and the star fruit and pineapple jam to the star fruit only jam. However, they said they would, recommend the star fruit jam for consumption.

\subsection{Conclusions of the Study}

From the findings of the results, the study first concludes that the production of star fruit jam was possible as can be seen from the study. The star fruit jam was accepted by the respondents as they indicated that the sensory attributes (that is, the color, taste, smell, flavor, texture, after-taste and consumer acceptability) of the pineapple, star fruits and the pineapple and star fruit jams were generally very good. Finally, most of the respondents preferred the pineapple jam and the star fruit and pineapple jam to the star fruit jam but they would however, recommend the star fruit jam for consumption. As such they would encouraged the patronage the star fruit jam. Starfruit jam is not a commonly consumed fruit in Ghana as compared to pineapple. It is also more expensive than the locally grown fruits and can be attested that due to it not been eaten frequently hence the respondent's preference of the pineapple and pineapple and starfruit jam as compared to the starfruit only jam.

\subsection{Recommendations of the Study}

From the findings and the conclusions of the study, it is recommended that there should be more education on star fruits, the nutritional value and health benefits to increase its consumption. Food and beverage manufacturing companies should be encouraged to use star for the production of jam to increase its life span especially when it is in season and also make it available when it is not in season. It is recommended that further research should be conducted to assess the possibility of using star fruit to produce other food products.

\section{References}

Bastin, S. (2004). The Science of jam and jelly making. Cooperative Extension Service. University of Kentucky. College of Agriculture.

Beauman, F. (2005). Pineapple, King of fruits. Collingdale United States: Diane Publishing Company.

Eagan, S. (2006). Small Scale Production of Food Preserves. Fact Sheet No. 16, Agriculture 
and Food Development Authority.

International Journal Food Science Nutrition. (2014). Impact of micronized starfruit (Averrhoa carambola L.) fiber concentrate on lipid metabolism in mice.

Joy, P. P., \& Abraham, M. (2013). Fruits, Benefits, Processing, Preservation and Pineapple recipes. Kerala India: Pineapple research station, Kerala Agricultural University.

Lawless, H. T., \& Heymann, H. (1998). Sensory Evaluation of Food: Principles and Practices. New York: Chapman \& Hall.

Leon, T. (2011). Health-Promoting Properties of Fruits and Vegetables (p. 92). CABI. [Online]

Available:

http://books.google.co.in/books?id=gNEZoC86dMQC\&dq=HealthPromoting+Properties+of

+Fruits+and+Vegetables+edited+by+Leon+Terry\&source=gbs_navlinks_s

McWilliams, M. (2005). Foods Experimental Perspectives (5th ed.) Upper Saddle River, New Jersey: Pearson - Prentice Hall.

Meiselman, H. L., \& Macfie, H. J. H. (1996). Food Choice Acceptance and Consumption (p. 239). Glasgow, UK: Backie Academic and Professional.

Mercola, J. (1996). What Is Star Fruit Good For? [Online] Available: http://foodfacts.mercola.com/star-fruit.html

Plunkett, J. W. (2006). Nutrition and Food Research and Education Centre for Global Food Issues. National Center for Home Food Preservation, University of Georgia, Athens. G. A.

Sidel, J. L., \& Stone, H. (1993). The role of sensory evaluation in the food industry. Food Quality \& Preference, 4, 65-73. San Diego: Academic Press.

Singh, R., Sharma, J., \& Goyal, P. K. (2014). Prophylactic Role of Averrhoa carambola (Star Fruit) Extract against Chemically Induced Hepatocellular Carcinoma in Swiss Albino Mice.

Singh-Ackbarali, D., \& Maharaj, R. (2014). Sensory Evaluation as a Tool in Determining Acceptability of Innovative Products Developed by Undergraduate Students in Food Science and Technology at The University of Trinidad and Tobago. Journal of Curriculum and Teaching, 3(1). [Online] Available: http://www.sciedu.ca/jct

Sonam. (2015, May 20). 13 Amazing Benefits of Star Fruit for Skin, Hair and Health. [Online] Available: http://www.stylecraze.com/articles/benefits-of-star-fruit-for-skin-hair-and-health

\section{Copyright Disclaimer}

Copyright for this article is retained by the author(s), with first publication rights granted to the journal.

This is an open-access article distributed under the terms and conditions of the Creative Commons Attribution license (http://creativecommons.org/licenses/by/3.0/). 